\title{
Comparison of septal and ventromedial hypothalamic lesion effects on discrete trial DRL behavior
}

\author{
FRANCIS W. FLYNN and JAMES C. MITCHELL \\ Kansas State University, Manhattan, Kansas 66506
}

\begin{abstract}
The performance of rats with ventromedial hypothalamic (VMH) or septal lesions was compared with that of normal subjects on a discrete trial DRL task. Animals were pretrained at $85 \%$ of their ad-lib body weights and postoperatively tested at this level of deprivation and at greater and lesser deprivation levels. Septal rats emitted significantly more nonreinforced responses and had shorter response latencies than did control and $\mathrm{VMH}$ rats while tested at the different deprivation levels. VMH lesioned rats performed as well as controls. Septal performance was not affected by deprivation level. Both VMH and control subjects obtained the greatest number of reinforcements while tested at the greater deprivation level. In spite of the large number of similarities between VMH and septal rats, VMH rats, unlike septal rats, used internal cues as well as normal rats did to perform proficiently on this task.
\end{abstract}

Rats with lesions of the ventromedial hypothalamus (VMH) and septum display a number of behavioral similarities. Such animals are hyperreactive to touch (Singh, 1969), overresponsive to orosensory characteristics of food (Beatty \& Schwartzbaum, 1967; Corbit \& Stellar, 1964; Singh \& Meyer, 1968), and possibly hyperphagic (Singh \& Meyer, 1968). Both septal and VMH rats display reduced spontaneous alternation activity in a T-maze (Singh, 1973a), decreased spontaneous behavior (Schwartzbaum \& Gay, 1966; Teitelbaum, 1961), and poor performance on passive avoidance tasks (Hamilton, Kelsey, \& Grossman, 1970; Margules \& Stein, 1969; Singh, 1973a). Furthermore, Kaada (1951) observed that electrical stimulation of either the septum or VMH depressed respiration and blood pressure and would inhibit spinal reflexes and movement elicited by cortical stimulation.

The behavioral similarities observed following septal and VMH lesions or stimulation suggest that these two areas are part of an inhibitory somatomotor system (Kaada, 1951, 1960). Van Hoesen, MacDougall, Wilson, and Mitchell (1971) have shown that septal rats perform poorly on a discrete trial DRL task (DT-DRL). During this task, the insertion of the lever into the operant chamber signals the start of the delay on DRL. The poor septal performance on this task was interpreted to indicate that septals are unable to organize collateral behaviors to bridge the delay period or to use response-produced cues.

This research was supported in part by NIH Biomedical Research Support Grant RR07036. Requests for reprints should be addressed to James C. Mitchell, Department of Psychology, Kansas State University, Manhattan, Kansas 66506.
In light of Kaada's hypothesis and the behavioral similarities of VMH and septal rats, it was of interest to see if VMH rats also perform similarly on a DT-DRL task.

Our initial observations showed no differences in performance between normal and VMH subjects, while septals performed less proficiently. In order to increase the likelihood of VMH-normal performance differences on this task, levels of food deprivation were subsequently manipulated.

\section{METHOD}

\section{Subjects}

Adult female rats of the Long-Evans strain were used $(N=15)$. All rats were housed individually in standard cages throughout the experiment. Subjects had free access to water throughout the experiment, but Purina Rat Chow availability was restricted according to the specified deprivation condition.

\section{Apparatus \\ Training and postoperative testing on the DT-DRL schedule were conducted in standard Lehigh Valley Electronics operant chambers (Model 1315). The operant chambers were equipped with retractable levers and feeding mechanisms that delivered single 45-mg Noyes food pellets as reinforcements. The retractable lever measured $22 \times 33 \mathrm{~mm}$ and required approximately $2.0 \mathrm{sec}$ to be fully inserted into or retracted from the chamber. All pro- gramming was automated. Leverpress responses were counted on digital counters that provided response latency distributions in 10 successive 4 -sec class intervals. Only those responses that occurred when the lever was fully extended into the operant chamber were recorded.}

\section{Procedure}

After being reduced to $85 \%$ of their free-feeding weights, the subjects were shaped to leverpress on a continuous reinforcement schedule (CRF) until 100 reinforcements were obtained. Animals were then switched to a schedule wherein a leverpress would deliver reinforcement and immediately retract the lever. The lever 
was reinserted following a randomly determined variable intertrial period with a mean duration of $12 \mathrm{sec}$. The houselight came on when the lever was fully extended and was turned off as the lever was retracted. Animals received 200 trials on this schedule.

A delay period was then introduced between the insertion of the lever and the opportunity for reinforcement. Leverpresses following this delay period delivered reinforcement and retracted the lever. Leverpressing during this delay period resulted in only retraction of the lever. In all schedules, an unlimited hold of reinforcement was used. Animals were given, successively, 5 days of training with a 5-sec delay schedule, 4 days on a 10-sec delay schedule, 3 days on a 15 -sec delay schedule, and 30 days on a final 20-sec delay schedule. On each day, all subjects were given 100 trials. This procedure and task are described in an earlier paper (Van Hoesen et al., 1971).

\section{Surgery}

Following 30 days of training on the 20 -sec delay schedule, rats were matched on the basis of response latency distributions and assigned to one of three conditions: control, VMH lesion, or septal lesion ( $n=5 /$ group). Surgery was performed under Chloropent anesthesia $(.30 \mathrm{ml} / 100 \mathrm{~g})$. Animals were mounted with their skulls level in a stereotaxic instrument, and bilateral lesions of the VMH were produced by passing a 2-mA dc anodal current through the uninsulated tip $(.5 \mathrm{~mm})$ of a stainless steel electrode for $15 \mathrm{sec}$. The stereotaxic coordinates for VMH lesions were: $2.5 \mathrm{~mm}$ posterior to bregma, $.5 \mathrm{~mm}$ lateral to midline, and $.8 \mathrm{~mm}$ dorsal from base of the skull. Animals receiving septal lesions were mounted in the stereotaxic instrument with the incisor bar positioned $5.0 \mathrm{~mm}$ above the horizontal interaural line. Bilateral septal lesions were produced by passing a $1.5 \mathrm{~mA}$ dc anodal current for $20 \mathrm{sec}$ through the uninsulated tip of the electrode that was positioned $1.5 \mathrm{~mm}$ anterior to bregma, $.5 \mathrm{~mm}$ lateral to midline, and $6.0 \mathrm{~mm}$ ventral to the surface of the skull. For both VMH lesions and septal lesions, the ear bars of the stereotaxic instrument served as the cathode.

The control rats were anesthetized and mounted in the stereotaxic instrument, but the integrity of the brain was not disrupted. All animats received 30,000 units Bicillin, im. They were returned to their home cages and allowed an undisturbed 7-day recovery period, during which ad-lib food and water were available, before being returned to food deprivation.

\section{Postoperative Procedure}

All animals were tested on the 20-sec DT-DRL schedule under three food-deprivation conditions. First, after reaching $85 \%$ freefeeding body weight (moderate deprivation level), rats were maintained and tested for 5 days at this body weight. Second, while maintained at $85 \%$ body weight, rats were further food deprived for $48 \mathrm{~h}$ prior to being tested (greater deprivation level). The rats were run every 3 days during this greater deprivation condition to allow them to return to $85 \%$ body weight before initiating another 48-h deprivation period. Following 5 test days under these conditions, rats were permitted ad-lib access to food and water for 3 weeks. Third, free-feeding animals were deprived of food for $24 \mathrm{~h}$ prior to testing (minimal deprivation level).
Following testing, ad-lib food was supplied for 2 days prior to initiating another 24-h deprivation period and subsequent testing. Data were recorded for five sessions under each of the three conditions.

\section{Histology}

Following the completion of testing, the experimental animals were deeply anesthetized and perfused successively with saline and $10 \%$ Formalin. Brains were extracted and fixed in sucroseFormalin. Frozen sections $30 \mu$ thick were taken, with every fifth section being saved and stained with cresyl violet. The extent of the lesions was determined under microscopic examination and by projecting the sections onto representative photomicrograph plates (Pellegrino, Pellegrino, \& Cushman, 1979).

\section{RESULTS}

\section{Lesion Placement}

Histological examination of the brain sections indicated that the septal lesions were large and quite consistent in placement. Lesions destroyed the septal area extending from the vicinity of the genu of the corpus callosum posteriorly to the columns of the fornix. The lesions were confined to the area between the corpus callosum and the anterior commissure, and the lateral boundaries were the lateral ventricles. There was minor sparing of the anteriormost portions of the septal nuclei and the ventral portion of the medial septal nucleus. Minor damage to the columns of the fornix was observed.

Lesions of the VMH were generally symmetrical. Destruction included the arcuate and periventricular nuclei. Damage was restricted medial to the fornix except for one rat, in which the lesion did damage the fornix unilaterally.

\section{DT-DRL 20-sec Performance}

Preoperatively, the three groups to which subjects were assigned did not differ significantly in the number of reinforced responses (Kruskal-Wallis analysis of variance) or on response latency. Table 1 presents the percentage of reinforced responses, mean response latencies, and body weights of control, septal, and VMH rats pre- and postoperatively. Figure 1 presents the distributions of response latencies for control, septal, and VMH rats when the subjects were tested at the three different deprivation levels. Postoperatively, when tested at $85 \%$ free-feeding body weight,

Table 1

Preoperative and Postoperative Measures of Mean Response Latency, Percent Reinforcement, and Body Weight During the Three Food-Deprivation Levels

\begin{tabular}{|c|c|c|c|c|c|c|c|c|c|}
\hline & \multicolumn{3}{|c|}{ Mean Latency } & \multicolumn{3}{|c|}{ Percent Reinforced } & \multicolumn{3}{|c|}{ Body Weight } \\
\hline & Control & VMH & Septal & Control & VMH & Septal & Control & VMH & Septal \\
\hline $\begin{array}{l}\text { Preoperative } \\
\text { Postoperative Moderate } \\
\text { Greater } \\
\text { Minimal }\end{array}$ & $\begin{array}{l}21.09 \\
20.20 \\
21.09 \dagger \\
19.10\end{array}$ & $\begin{array}{l}21.49 \\
20.90 \\
21.97 \\
18.45\end{array}$ & $\begin{array}{l}21.03 \\
11.55^{*} \\
12.04^{*} \\
12.65^{*}\end{array}$ & $\begin{array}{l}56.8 \\
45.8 \\
53.6 * * \dagger \\
40.0\end{array}$ & $\begin{array}{l}54.3 \\
50.6 \\
56.2^{* *} \\
40.0\end{array}$ & $\begin{array}{r}52.1 \\
9.8^{*} \\
8.4^{*} \\
7.1^{*}\end{array}$ & $\begin{array}{l}277.8 \\
282.5 \\
268.2 \\
304.7\end{array}$ & $\begin{array}{l}275.0 \\
296.3 \\
285.4 \\
385.0^{*}\end{array}$ & $\begin{array}{l}276.3 \\
272.6 \\
246.7^{*} \\
310.0\end{array}$ \\
\hline
\end{tabular}

*Differs from control group at that deprivation level $(p<.05)$.

**Differs from performance at moderate deprivation level $(p<.05)$.

tDiffers from performance at minimal deprivation level $(p<.05)$. 

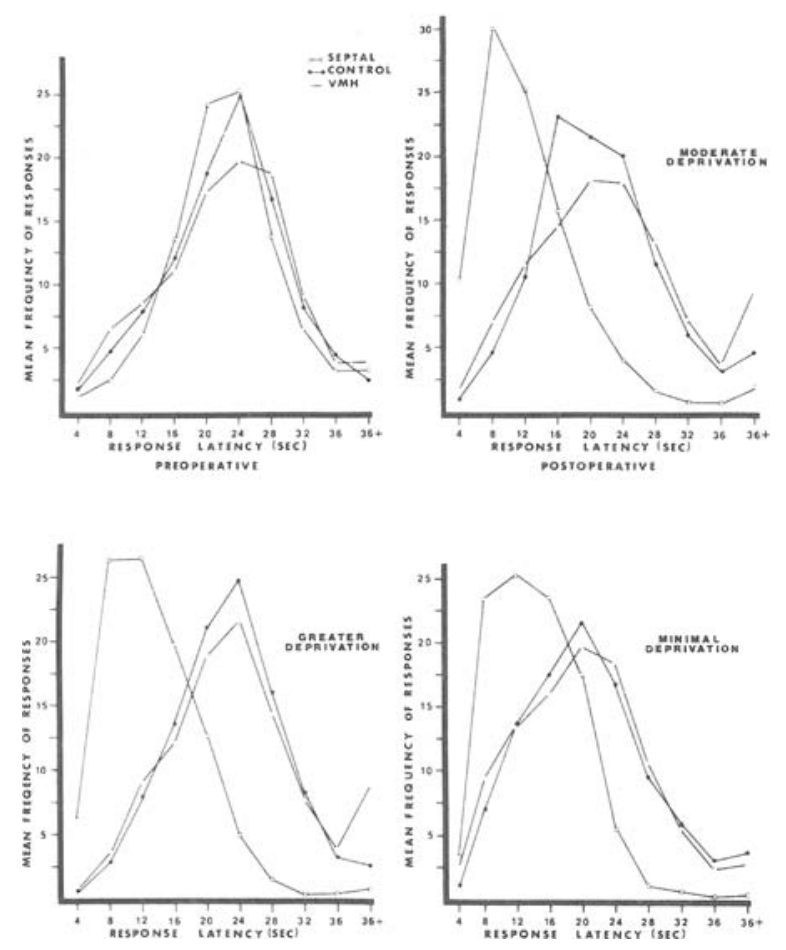

Figure 1. Mean preoperative and postoperative response latency distributions of control, septal, and VMH rats while tested at the moderate (85\% free-feeding weight), greater ( $85 \%$ free-feeding plus 48-h food deprivation), and minimal (ad-lib) deprivation levels.

control, septal, and VMH rats differed significantly in the percentage of reinforced responses $(\mathrm{H}=9.5$, $\mathrm{p}<.009)$ and response latency $(\mathrm{H}=9.7, \mathrm{p}<.009)$. Mann-Whitney tests revealed that septal rats obtained significantly fewer reinforcements than did controls and $\mathrm{VMH}$ rats $(\mathrm{Us}=0$, ps $<.004)$. $\mathrm{VMH}$ and control rats did not differ significantly in the number of reinforcements obtained or in response latency.

Control, septal, and VMH rats continued to differ significantly in the percentage of reinforced responses and in response latency when tested at the greater deprivation level $(\mathrm{H}=9.38, \mathrm{p}<.009$, and $\mathrm{H}=9.62$, $\mathrm{p}<.009$, respectively) and when tested at the minimal deprivation level $(\mathrm{Hs}=8.9$, ps $<.01)$. During these two deprivation conditions, septal rats emitted significantly fewer reinforced responses than did controls and $\mathrm{VMH}$ rats $(\mathrm{Us}=9$, ps $<.004)$. Furthermore, septal rats continued to emit responses of shorter latency than did control and VMH rats $(\mathrm{Us}=0$, ps $<.004)$. During the greater and minimal deprivation levels, control and VMH rats did not differ on either the percentage of reinforced responses or response latency.

Repeated measures analyses of variance and Newman-Keuls tests were computed to assess the influence that deprivation level had on the percentage of reinforced responses and response latencies of control, septal, and VMH rats (see Table 1 and Fig- ure 1). There were no systematic changes in the percentage of reinforced responses or response latency for septal rats across the three deprivation levels. In contrast, deprivation condition did significantly influence the percentage of reinforced responses for control $[\mathrm{F}(2,8)=10.7, \mathrm{p}<.05]$ and $\mathrm{VMH}$ subjects $[\mathrm{F}(2,8)=5.3, \mathrm{p}<.05]$. Individual comparisons revealed that control rats received significantly more reinforcements at the greater deprivation level than while tested at the moderate and minimal deprivation levels (ps <.05). Similarly, VMH rats obtained a significantly greater percentage of reinforcement while tested at the greater deprivation level than at the minimal deprivation level $(\mathrm{p}<.05)$.

Correspondingly, deprivation condition influenced the latency of responding for controls $[F(2,8)=7.6$, $\mathrm{p}<.05]$. During the minimal deprivation condition, controls displayed significantly shorter response latency than they did while tested at the greater deprivation level $(p<.05)$. The VMH subjects did not show any significant changes in response latency across the deprivation levels.

\section{Body Weight}

Body weights of control, septal, and $\mathrm{VMH}$ rats were not significantly different while tested at the moderate deprivation level. VMH and control body weights were not significantly different while maintained at the greater deprivation level, but both groups were significantly heavier than septals during this period (ps <.05). VMH rats were significantly heavier than septal and control rats after being allowed ad-lib food and tested at the minimal deprivation level (ps < .05). Furthermore, VMH rats weighed significantly more during the minimal deprivation than when tested during the moderate and greater deprivation levels ( $\mathrm{ps}<.05)$.

\section{DISCUSSION}

Rats with VMH lesions performed as well as controls on the food-motivated DT-DRL task. In contrast, septal rats emitted responses of shorter latency and, hence, obtained fewer reinforcements than control and VMH rats. The deficit of septal rats on this task replicates an earlier report (Van Hoesen et al., 1971). While VMH and septal rats display similar behaviors and perform comparably on a variety of tasks (Hamilton et al., 1970; Singh, 1973a), this similarity was not observed on the DT-DRL task. This shows that, unlike the septal rat, VMH rats use the internal cues available to organize and maintain patterns of collateral behavior during the delay period as well as normal rats do.

Response inhibition interpretations have been offered for both VMH and septal operant performance (Margules \& Stein, 1969; McCleary, 1966; Singh, 1973a). However, this type of interpretation seems unsatisfactory since rats with septal lesions do suppress 
responding: (1) on a DRL schedule when an exteroceptive cue is provided signaling the end of the delay period (Ellen \& Butter, 1969); (2) when a particular class of interresponse times is differentially reinforced (Ellen, Makohon, \& Richardson, 1978); and (3) on a Sidman avoidance task (Morgan \& Mitchell, 1969; Sodetz, 1970). The present study demonstrates that VMH rats do not seem to have an inability to suppress responding, and, unlike septal rats, they do appear to be able to use internal cues to perform proficiently on this task.

Deprivation and the resulting effect upon body weight did not influence the performance of septal rats. Control and VMH rats obtained more reinforcements while performing at the lower body weight level. Many of those tasks on which VMH subjects perform poorly (Miller, Bailey, \& Stevenson, 1950; Teitelbaum, 1957) place a premium on motor skills or rapid rates of responding. The ponderousness of the VMH animal, rather than the lowered food motivation (Miller et al., 1950; Teitelbaum, 1957), may account for poor performance by VMH subjects on operant tasks (Sclafani \& Kluge, 1974; Wampler, 1973). It is unlikely that proficient performance on DT-DRL places demands on motor skills and ability. Had ponderousness or lack of motor ability influenced performance on this task, the VMH rats in this study would be expected to have longer response latencies. This was not observed.

In addition to VMH obesity, a second factor that may determine VMH performance is the heightened emotionality displayed by these subjects. Preoperative training may attenuate the hyperemotionality displayed by the VMH subjects and therefore account for the improved operant performance displayed by preoperatively trained rats (Peters, Sensenig, \& Reich, 1973; Singh, 1973b). Flynn, Schirer, and Mitchell (1980) and Peters et al. (1973) have reported that extensive preoperative handling reduces VMH emotionality. However, both septal and VMH rats showed a reduction in emotionality during testing on DT-DRL, indicating that this does not account for operant performance differences.

\section{REFERENCES}

Beatty, W. W., \& Schwartzbaum, J. A. Enhanced reactivity to quinine and saccharin solutions following septal lesions in rats. Psychonomic Science, 1967, 8, 483-484.

Corbit, J. D., \& Stellar, E. Palatability, food intake, and obesity in normal and hyperphagic rats. Journal of Comparative and Physiological Psychology, 1964, 58, 63-67.

Ellen, P., \& Butter, J. External cue control of DRL performance in rats with septal lesions. Physiology \& Behavior, 1969, 4, 1-6.

Ellen, P., Makohon, L., \& Richardson, W. K. Response suppression on DRL by rats with septal damage. Journal of Comparative and Physiological Psychology, 1978, 92, 511-521.

Flynn, F. W., Schirer, D. L., \& Mitchell, J. C. Reduced salivation in rats following ventromedial hypothalamic lesions. Physiology \& Behavior, 1980, 24, 451-455.
Hamilton, L., Kelsey, J. E., \& Grossman, S. P. Variation in behavioral inhibition following different septal lesions in rats. Journal of Comparative and Physiological Psychology, 1970, 70, 79-86.

KAADA, B. R. Somato-motor, autonomic and electrocorticographic responses to electrical stimulation of "rhinencephalic" and other structures in primate, cat, and dog. Acta Physiologica Scandinavica, 1951, 24, Suppl. 83, 1-258.

KAADA, B. R. Cingulate, posterior orbital, anterior insular and temporal pole cortex. In J. Field, H. W. Magoun, \& V. E. Hall (Eds.), Handbook of physiology (Vol. 2): Neurophysiology. Washington, D.C: American Physiological Society, 1960.

Margules, D. L., \& Stein, L. Cholinergic synapses in the ventromedial hypothalamus for the suppression of operant behavior by punishment and satiety. Journal of Comparative and Physiological Psychology, 1969, 67, 327-335.

MCCleary, R. A. Response-modulating functions of the limbic system: Initiation and suppression. In E. Stellar \& J. M. Sprague (Eds.), Progress in physiological psychology (Vol. 1). New York: Academic Press, 1966.

Miller, N. E., Bailey, C. J., \& Stevenson, J. A. F. Decreased "hunger" but increased food intake resulting from hypothalamic lesions. Science, 1950, 112, 256-259.

Morgan, J. M., \& Mitchell, J. C. Septal lesions enhance delay of responding on a free operant avoidance schedule. Psychonomic Science, 1969, 16, 10-11.

Pellegrino, L. J., Pellegrino, A. S., \& Cushman, A. J. $A$ stereotaxic atlas of the rat brain. New York: Plenum Press, 1979.

Peters, R., Sensenig, L. D., \& Reich, M. J. Fixed-ratio performance following ventromedial hypothalamic lesions in rats. Physiological Psychology, 1973, 1, 136-138.

Schwartzbaum, J. S., \& GAY, P. E. Interacting between behavioral effects of septal and amygdaloid lesions in the rat. Journal of Comparative and Physiological Psychology, 1966, 61, 59-65.

Sclafani, A., \& Kluge, L. Food motivation and body weight levels in hypothalamic hyperphagic rats. Journal of Comparative and Physiological Psychology, 1974, 86, 28-46.

SiNGH, D. Comparison of hyperemotionality caused by lesions in the septal and ventromedial hypothalamic areas in the rat. Psychonomic Science, 1969, 16, 3-4.

Singh, D. Comparison of behavioral deficits caused by lesions in septal and ventromedial hypothalamic areas of female rats. Journal of Comparative and Physiological Psychology, 1973, 84, 370-379. (a)

Singh, D. Effects of preoperative training on food-motivated behavior of hypothalamic hyperphagic rats. Journal of Comparative and Physiological Psychology, 1973, 84, 47-52. (b)

SingH, D., \& MEYER, D. R. Eating and drinking by rats with lesions of the septum and the ventromedial hypothalamus. Journal of Comparative and Physiological Psychology, 1968, 65, 163-166.

SoDETz, F. J. Septal ablation and free-operant avoidance behavior in the rat. Physiology \& Behavior, 1970, 5, 1255-1259.

Teitelbaum, P. Random and food directed activity in hyperphagic and normal rats. Journal of Comparative and Physiological Psychology, 1957, 50, 486-490.

Teitelbaum, P. Disturbances in feeding and drinking after hypothalamic lesions. In M. R. Jones (Ed.), Nebraska Symposium on Motivation. Lincoln: University of Nebraska Press, 1961.

Van Hoesen, G. W., MacDougall, J. M., Wilson, J. R., \& Mitchell, J. C. Septal lesions and the acquisition and maintenance of a discrete-trial DRL task. Physiology \& Behavior, 1971, 7, 471-475.

WAMPLER, R. S. Increased motivation in rats with ventromedial hypothalamic lesions. Journal of Comparative and Physiological Psychology, 1973, 84, 275-285.

(Received for publication April 14, 1980; revision accepted July 16,1980 .) 